\title{
Prescripción de ejercicio en pacientes con fibromialgia
}

Prescribed exercise in people with fibromialgia: parallel group randomised controlled trial. Richards S, Scott D. BMJ. 2002 July 27; 325:185-187.

\section{Objetivo}

Evaluar el ejercicio físico aeróbico en pacientes con fibromialgia.

\section{Diseño}

Ensayo clínico controlado aleatorizado.

\section{Lugar}

Hospital ambulatorio de Reumatología, Londres.

Los programas de ejercicio tuvieron lugar en centros de actividad física, extrahospitalarios.

\section{Pacientes}

136 pacientes con fibromialgia diagnosticada según los criterios del Colegio Americano de Reumatología de 1990. Hombres $(n=10)$ y mujeres $(n=126)$ entre 18 a 70 años.

Se excluyeron pacientes con diagnóstico clínico alternativo que podrían explicar los síntomas actuales, pacientes con incapacidad física severa, y aquellos que no podían concurrir a las clases por otros motivos.

\section{Intervención}

Se aleatorizó a los pacientes en dos grupos de tratamiento.Un grupo recibió tratamiento activo de ejercicios aeróbicos graduados a través de bicicleta fija y caminata en cinta sin fin. El otro grupo realizó tratamiento control consistente en ejercicios de relajación y flexibilidad caracterizados por estiramiento de miembros superiores e inferiores y técnicas de relajación.

La duración de la intervención fue de 12 semanas, con clases de 1 hora, 2 veces por semana.Cada individuo fue alentado a incrementar la intensidad de ejercicios mientras lo consideraran tolerable. Al inicio de las clases realizaban dos períodos de 6 minutos cada uno; a los 3 meses dos períodos de 25 minutos con una intensidad que les provocara sudoración moderada y les permitiera hablar confortablemente en oraciones completas.

Los pacientes respondieron cuestionarios y se sometieron a examen físico antes del tratamiento, a los 3, 6 y 12 meses, realizado por un asesor ciego a la intervención.Los pacientes continuaron con la medicación previa al estudio y recibieron información sobre la fibromialgia.

La intervención fue coordinada por un entrenador físico ciego a la hipótesis del ensayo, sin experiencia en trabajo con personas enfermas.

\section{Medición de resultados principales}

El resultado principal se definió como grado de cambio en la impresión personal global de la enfermedad por medio de una escala de 7 puntos:1(mucho peor) a 7 (mucho mejor).Se consideraron como respondedores: score 6 y 7; no respondedores:score menor y pacientes que no concurrieron a clases.Los instrumentos utilizados para medir los resultados:fueron dos:fibromyalgia impact questionnaire, and short form McGill pain questionnaire.El análisis fue por intención de tratar*.

\section{Medición de resultados secundarios}

Cuantificación de 18 puntos dolorosos definidos para fibromialgia. Impacto de la enfermedad por la evaluación de síntomas, discapacidad, fatiga física y mental.

\section{Resultados principales}

A los tres meses $24 / 69$ (35\%) de los participantes del grupo ejercicio aeróbico estaban mejor y mucho mejor (score 6 y 7) comparado con 12/67 (18\%) de los que realizaron relajación( $P=0.03)$.Abandonaron 12 participantes en cada grupo.

A los doce meses se mantuvieron los beneficios en 26 (38\%) y 15 (22\%) participantes respectivamente $(P=0.06)$

\begin{tabular}{l|l|l|c|c|c} 
& $\begin{array}{l}\text { GRUPO AEROBICO } \\
\mathrm{N}=69(51 \%)\end{array}$ & $\begin{array}{l}\text { GRUPO RELAJACION } \\
\mathbf{N}=67(49 \%)\end{array}$ & RRA & $\begin{array}{c}\text { NNT } \\
(\text { IC95\%) }\end{array}$ & $\mathbf{P}$ \\
\hline $\begin{array}{l}\text { MEJORIA } \\
3 \text { MESES }\end{array}$ & $24(35 \%)$ & $12(18 \%)$ & $17 \%$ & $6(3 \mathrm{a} 42)$ & 0.03 \\
\hline $\begin{array}{l}\text { MEJORIA } \\
12 \text { MESES }\end{array}$ & $26(38 \%)$ & $15(22 \%)$ & $16 \%$ & NS & 0.06 \\
\hline
\end{tabular}

\section{Resultados secundarios}

A los tres meses descendió significativamente la cuantificación de los puntos dolorosos en ambos grupos. Esto se mantuvo por doce meses y fue más favorable para el grupo de ejercicios aeróbicos: diferencia en puntos dolorosos=2.2 (95\% IC 0.6-3.7) $\mathrm{P}=0.02$

A los doce meses sólo 75 (55\%) de los participantes reunían criterios de fibromialgia: 31 del grupo ejercicio aeróbico y 44 del grupo relajación ( $\mathrm{P}=0.02)$

Los otros resultados secundarios no difirieron entre los grupos.

\section{Conclusión}

Prescribir ejercicio aeróbico graduado es un tratamiento simple, económico, efectivo y accesible para los pacientes con fibromialgia.

Fuente de financiamiento:NHS (National Health Service).

\section{Comentario}

Este estudio demuestra que los ejercicios aeróbicos graduados producen a los tres meses beneficios significativos en la valoración personal de la enfermedad y que la cuantificación de los puntos dolorosos y el impacto de la fibromialgia también mejoraron. Debido a la afectación física que produce esta enfermedad y a lo subjetivo de la sintomatología, consideramos que la valoración de la impresión del paciente sobre la mejoría de su estado a través de una escala constituye una herramienta válida y fidedigna para evaluar el efecto del ejercicio.

Los estudios previos publicados describen el efecto beneficioso del ejercicio realizado en centros especializados y por profesionales de la salud entrenados en la atención de este tipo de pacientes. Este estudio agrega a los anteriores que la prescripción de ejercicios puede llevarse a cabo efectivamente en la comunidad con la supervisión de entrenadores físicos inexpertos en el manejo de pacientes con fibromialgia.

Conclusiones de los comentadores: La limitación al tratamiento con ejercicios es la adherencia, con alta frecuencia de abandono debido al incremento inicial del dolor y rigidez posterior al ejercicio, además de la creencia de los pacientes sobre la posibilidad de empeoramiento de su condición.El médico podría tranquilizar al paciente y alentarlo a que continúe ya que el efecto final será beneficioso.

Potenciales estrategias adicionales incluyen terapia cognitiva conductual y explicación psicológica de los síntomas. 